\title{
Kinetics of phosphate absorption in lactating dairy cows after enteral administration of sodium phosphate or calcium phosphate salts
}

\author{
Walter Grünberg ${ }^{1 *}$, Paul Dobbelaar ${ }^{1}$ and Gerhard Breves ${ }^{2}$ \\ ${ }^{1}$ Department of Farm Animal Health, Utrecht University, Utrecht, The Netherlands \\ ${ }^{2}$ Physiologisches Institut, Stiftung Tierärztliche Hochschule Hannover, Germany
}

(Submitted 16 April 2012 - Final revision received 3 January 2013 - Accepted 4 January 2013 - First published online 2 April 2013)

\section{Abstract}

Hypophosphataemia is frequently encountered in dairy cows during early lactation. Although supplementation of $\mathrm{P}$ is generally recommended, controversy exists over the suitability of oral $\mathrm{P}$ supplementation in animals with decreased or absent rumen motility. Since the effects of transruminal $\mathrm{P}$ absorption and the reticular groove reflex on the absorption kinetics of $\mathrm{P}$ are not well understood, it is unclear in how far treatment efficacy of oral $\mathrm{P}$ supplementation is affected by decreased rumen motility. Phosphate absorption was studied in six phosphate-depleted dairy cows fitted with rumen cannulas and treated with test solutions containing either $\mathrm{NaH}_{2} \mathrm{PO}_{4}$ or $\mathrm{CaHPO}_{4}$ with acetaminophen. Each animal was treated orally, intraruminally and intra-abomasally in randomised order. Absorption kinetics of $\mathrm{P}$ were studied and compared with the absorption kinetics of acetaminophen, a marker substance only absorbed from the small intestine. Intra-abomasal treatment with $\mathrm{NaH}_{2} \mathrm{PO}_{4}$ resulted in the most rapid and highest peaks in plasma inorganic $\mathrm{P}\left(\mathrm{P}_{\mathrm{i}}\right)$ concentration. Oral and intraruminal administration of $\mathrm{NaH}_{2} \mathrm{PO}_{4}$ resulted in similar increases in plasma $\mathrm{P}_{\mathrm{i}}$ concentration from 4 to $7 \mathrm{~h}$ in both groups. Treatment with $\mathrm{NaH}_{2} \mathrm{PO}_{4}$ caused more pronounced peaks in plasma $\mathrm{P}_{\mathrm{i}}$ concentration compared with CaHPO 4 . Neither transruminal $\mathrm{P}$ absorption nor the reticular groove reflex affected $\mathrm{P}$ absorption kinetics as determined by comparing plasma concentration-time curves of $\mathrm{P}$ and acetaminophen after administration of $1 \mathrm{M}$-phosphate salt solutions. It is concluded that oral treatment with $\mathrm{NaH}_{2} \mathrm{PO}_{4}$ but not $\mathrm{CaHPO}_{4}$ is effective in supplementing $\mathrm{P}$ in hypophosphataemic cows with adequate rumen motility. Decreased rumen motility is likely to hamper the efficacy of oral phosphate treatment.

\section{Key words: Phosphate absorption: Hypophosphataemia: Dairy cows}

Phosphorus homeostasis in dairy cattle has received increased attention recently because of the possible association between hypophosphataemia and the downer cow syndrome as well as because of increasing concerns about the environmental impact of excessive amounts of $\mathrm{P}$ in manure ${ }^{(1,2)}$. In an effort to reduce faecal $\mathrm{P}$ output, the National Research Council recently reduced dietary $\mathrm{P}$ recommendations for dairy cows, with the justification that a lower $\mathrm{P}$ intake does not interfere with fertility, milk yield or health of dairy cattle ${ }^{(3)}$. Nonetheless, with continuously increasing productivity of the modern dairy cow, $\mathrm{P}$ requirements concomitantly increase, thereby presenting a growing challenge for the regulation of $\mathrm{P}$ homeostasis, particularly at the onset of lactation when cows suddenly change from a period of low $\mathrm{P}$ requirements to a phase of high $\mathrm{P}$ requirements while feed intake is at its nadir ${ }^{(4)}$.

Hypophosphataemia is commonly observed in early lactating cows with a number of periparturient diseases such as milk fever, abomasal disorders or fatty liver ${ }^{(4-6)}$. Although hypophosphataemia is considered to be a consequence rather than the cause of these conditions, treatment of hypophosphataemia is nonetheless recommended in the literature because $\mathrm{P}$ depletion is associated with anorexia, which may aggravate the clinical presentation of a sick animal and hamper or delay recovery from disease ${ }^{(4,7)}$. Treatment of hypophosphataemia in ruminants consists of either oral or parenteral administration of phosphate salts. Whereas sodium phosphate salts are most commonly used for either

\footnotetext{
Abbreviations: AP, acetaminophen; $\mathrm{AUC}_{\mathrm{AP} 60}$, area under plasma acetaminophen concentration-time curve for the first 60 min; $\mathrm{AUC} \mathrm{AP}_{20}$, area under the plasma acetaminophen concentration-time curve for the first $120 \mathrm{~min}$; AUC $\mathrm{PDiff}_{120}$, area under plasma inorganic $\mathrm{P}$ concentration increment-time curve for the first $120 \mathrm{~min}$; $\mathrm{AUC}_{\mathrm{PDiff} 240}$, area under plasma inorganic $\mathrm{P}$ concentration increment-time curve for the first $240 \mathrm{~min}$; CaAbo, CaHPO, administered into the abomasum; $\mathrm{C}_{\mathrm{APmax}}$, maximal acetaminophen concentration; CaRu, $\mathrm{CaHPO}_{4}$ administered into the ventral rumen sac; $\mathrm{C}_{\mathrm{Pmax}}$,

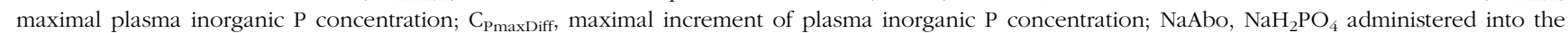
abomasum; NaOr, $\mathrm{NaH}_{2} \mathrm{PO}_{4}$ administered orally; $\mathrm{NaRu}, \mathrm{NaH}_{2} \mathrm{PO}_{4}$ administered into the ventral rumen sac; $\mathrm{P}_{\mathrm{i}}$, inorganic $\mathrm{P}$; $\mathrm{T}_{\mathrm{A}}$ max , time to maximal plasma acetaminophen concentration; $\mathrm{T}_{\mathrm{Pmax}}$, time to maximal plasma inorganic $\mathrm{P}$ concentration.
} 
oral or intravenous treatment in cattle, calcium phosphate salts have also been proposed for oral treatment in periparturient dairy cows because hypophosphataemia in these animals is frequently associated with hypocalcaemia ${ }^{(4)}$.

Controversy exists over the most appropriate therapeutic approach for hypophosphataemia in dairy cattle. Whereas some authors deem oral treatment of hypophosphataemia unsuitable because of a minimal effect and a time delay of several hours between oral treatment and increase of plasma inorganic $\mathrm{P}\left(\mathrm{P}_{\mathrm{i}}\right)$ concentration, other studies report marked peaks in plasma $\mathrm{P}_{\mathrm{i}}$ concentration within $1-2 \mathrm{~h}$ of oral treatment $^{(8-10)}$. Debate also exists over the role of the reticulorumen as a site of $\mathrm{P}_{\mathrm{i}}$ absorption and of the reticular groove reflex in adult cattle ${ }^{(11,12)}$. Although the permeability of the rumen mucosa for $P_{i}$ is well documented, the importance of the reticulorumen as a site for $\mathrm{P}_{\mathrm{i}}$ absorption has been questioned, as only insignificant amounts of $\mathrm{P}_{\mathrm{i}}$ appear to cross the rumen wall ${ }^{(11)}$. The effect of oral administration of phosphate salts on the reticular groove reflex has received little attention in the past although a functioning groove reflex would have the potential to markedly improve phosphate absorption kinetics and could thus explain plasma $\mathrm{P}_{\mathrm{i}}$ concentration peaks occurring shortly after treatment. Although results are inconsistent, $\mathrm{Na}$ salts such as $\mathrm{NaHCO}_{3}$ or $\mathrm{NaCl}$ have been reported to be able to trigger the reticular groove reflex at least incidentally. The effect of sodium phosphate on the reticular groove to our knowledge has not yet been studied ${ }^{(12)}$.

The objective of the present study was therefore to study the absorption kinetics of $\mathrm{P}_{i}$ after enteral administration of different phosphate salts, focusing on $\mathrm{P}_{\mathrm{i}}$ absorption from the reticulorumen and the role of the reticular groove reflex. It was hypothesised that transruminal $\mathrm{P}_{\mathrm{i}}$ absorption in adult cattle would be quantitatively negligible and that the reticular groove reflex would not consistently be triggered by oral administration of sodium phosphate salt solutions.

\section{Materials and methods}

\section{Animals, housing, and feeding}

The national and institutional guidelines for the care and use of experimental animals were followed and all experimental procedures were approved by the Utrecht University Institutional Animal Care and Use Committee (DEC; permit no 2011.III.08.087).

A total of six healthy lactating and non-pregnant HolsteinFriesian cows fitted with permanent rumen cannulas were used for this experiment. Cows included in the present study were aged between 3 and 4.5 years and weighed between 526 and $658 \mathrm{~kg}$. Mean milk production over $305 \mathrm{~d}$ of the first lactation was 6950 (SD 842) kg. All cows were between 50 and 150 days in milk of their second or third lactation and were healthy on the basis of physical examination. Animals were housed in individual tie stalls bedded with rubber mats covered with sawdust in a temperature-controlled environment. Feed was offered twice daily between 06.00 and 07.00 hours and between 18.00 and 19.00 hours as total mixed
Table 1. Ingredients and composition of the total mixed ration (TMR) fed during the acclimatisation and experimental phases

\begin{tabular}{lc}
\hline & $\mathrm{DM}(\mathrm{g} / \mathrm{kg})$ \\
\hline Ingredients $^{*}$ & \\
Wilted grass silage & 262 \\
Maize silage & 489 \\
Soyabean meal & 124 \\
Perennial ryegrass seed straw & 24 \\
Beet pulp & 79 \\
Rapeseed meal & 22 \\
Chemical analysis & \\
DM (as fed) & 475 \\
Neutral-detergent fibre & 393 \\
Starch & 273 \\
Crude protein & 143 \\
Na & $93 \cdot 7$ \\
K & $13 \cdot 0$ \\
Ca & $5 \cdot 4$ \\
P & 3.0 \\
Mg & 2.5 \\
\hline * Urea (10 g/cow per feeding) was manually mixed into the TMR at the time of \\
feeding.
\end{tabular}

ration (TMR) based on maize silage, grass silage, soyabean meal, beet pulp, perennial ryegrass seed straw and urea formulated to meet the requirements of lactating dairy cows based on the recommendations of the National Research Council (NRC) with the exception of $\mathrm{P}$ content (Table 1$)^{(13)}$. The $\mathrm{P}$ content of the ration DM was slightly below NRC recommendations (3.2-4.2 g P/kg DM for lactating dairy cows) in order to induce mild hypophosphataemia in the studied animals ${ }^{(13)}$. Cows enrolled in the present study were allowed to adjust to this diet for $7 \mathrm{~d}$ before the first experimental treatment was administered. To minimise day-by-day variation in feed composition the TMR for the entire trial period was mixed on the same day in two batches. The feed was then packed in plastic bins and stored at $-24^{\circ} \mathrm{C}$ until fed. Cows were milked twice daily between 06.00 and 07.00 hours and between 18.00 and 19.00 hours.

\section{Experimental study}

All cows underwent five treatments in randomised order consisting of administration of a test solution containing either $302 \mathrm{~g} \mathrm{NaH}_{2} \mathrm{PO}_{4}$ dihydrate or $333 \mathrm{~g} \mathrm{CaHPO}_{4}$ dihydrate dispersed in 2 litres of deionised water at approximately $38^{\circ} \mathrm{C}$. These amounts of $\mathrm{NaH}_{2} \mathrm{PO}_{4}$ dihydrate and $\mathrm{CaHPO}_{4}$ dihydrate contain approximately $60 \mathrm{~g}$ of $\mathrm{P}_{\mathrm{i}}$, equivalent to the amount of $P_{i}$ recommended in the current literature for oral $P_{i}$ supplementation in dairy cattle $e^{(8,14)}$. Test solutions were either administered orally, into the ventral rumen sac or into the abomasum with a washout period of $48 \mathrm{~h}$ between treatments. Administration into the ventral rumen sac was achieved by inserting a large-bore silicone tube through the rumen cannula into the ventral rumen sac. The test solution was then infused within $1 \mathrm{~min}$ while the tip of the tube was manually kept in place. The silicone tube was then removed without further stirring the rumen content. For intra-abomasal infusion a large-bore silicone tube was passed from the rumen cannula 
through the reticulo-omasal and omaso-abomasal orifice into the abomasum. The correct position of the tip of the tube was confirmed by manually feeling the smooth abomasal mucosa while holding the tube in place. Deionised water $(500 \mathrm{ml})$ was first passed through the tube and the absence of back-flow of fluid at the height of the omaso-abomasal orifice was determined manually, confirming proper flow into the abomasum. The test solution was then infused within 1 min while manually maintaining the tip of the tube in the abomasum and paying attention to turbulences at the height of the omaso-abomasal orifice that would be suggestive of back-flow of part of the test solution into the forestomach system. For oral administration a drench gun commonly used in cattle practice was inserted into the buccal cavity repeatedly and $250 \mathrm{ml}$ of the test solution was administered at a time. No attempt was made to quantify the volume of test solution that was spilled during oral administration. The treatment groups were: (a) $\mathrm{CaRu}\left(\mathrm{CaHPO}_{4}\right.$ administered into the ventral rumen sac); (b) $\mathrm{CaAbo}\left(\mathrm{CaHPO}_{4}\right.$ administered into the abomasum); (c) NaRu $\left(\mathrm{NaH}_{2} \mathrm{PO}_{4}\right.$ administered into the ventral rumen sac); (d) NaAbo $\left(\mathrm{NaH}_{2} \mathrm{PO}_{4}\right.$ administered into the abomasum); and (e) $\mathrm{NaOr}\left(\mathrm{NaH}_{2} \mathrm{PO}_{4}\right.$ administered orally).

Acetaminophen (AP; $N$-acetyl-4-aminophenol) was added to each test solution at a dose of $50 \mathrm{mg} / \mathrm{kg}$ body weight. When administered orally AP is absorbed from the small intestines with the rate-limiting step for absorption being the rate of gastric emptying in animals with normal small-intestinal function $^{(15)}$. In the present study $\mathrm{AP}$ was used to confirm proper administration of the test solution into the abomasum and to determine the role of the reticular groove when administering $\mathrm{NaH}_{2} \mathrm{PO}_{4}$ orally. These objectives were achieved by comparing the plasma AP concentration curve after oral administration with the concentration curve after intraruminal infusion ( $=$ no closure of the reticular groove) and intraabomasal infusion of the test solution (= complete closure of the reticular groove). Comparison of the plasma AP and $P_{i}$ concentration-time curve was used as a crude parameter to assess the degree of transruminal $\mathrm{P}_{\mathrm{i}}$ absorption after intraruminal administration of $\mathrm{NaH}_{2} \mathrm{PO}_{4}$ or $\mathrm{CaHPO}_{4}$.

A 16-gauge catheter (Angiocath; Becton-Dickinson) was aseptically fitted into a jugular vein at least $12 \mathrm{~h}$ before the first treatment to which an extension set (Discofix C-3, $10 \mathrm{~cm}$; Braun Melsungen AG) was attached for blood collection. Cows were weighed using a calibrated digital large-animal scale in the evening before the first treatment. The determined weight was used to calculate the amount of AP to be added to each test solution.

Treatments were administered on the trial days between 09.00 and 09.30 hours and at least $2 \mathrm{~h}$ after feeding. Blood samples were obtained from the jugular catheter immediately before treatment as well as at 15, 30, 45, 60, 75, 90, 105, 120, 150, 180, 210, 240, 300, 420, 480, 720 and $1440 \mathrm{~min}$ after each treatment. At each sampling time, the catheter was flushed with $3 \mathrm{ml}$ of heparinised saline (40 IU of sodium heparin per $\mathrm{ml}$ of $0.9 \% \mathrm{NaCl}$ ) and $5 \mathrm{ml}$ of blood were withdrawn through the catheter. A quantity of $10 \mathrm{ml}$ blood was then aspirated into a separate syringe and immediately transferred to a $10 \mathrm{ml}$ tube containing lithium heparin as anticoagulant. Blood was kept at room temperature and centrifuged within $30 \mathrm{~min}$ of collection at $1500 \boldsymbol{g}$ for $15 \mathrm{~min}$ at room temperature. Harvested plasma was stored at $-24^{\circ} \mathrm{C}$ until analysed.

In the morning of each study day rumen cannula lids were replaced by specially prepared lids through which a smallbore silicone tube was passed into the ventral rumen sac for rumen fluid collection. The intraruminal tip of the tube was attached to a cage magnet, serving as weight that was placed in the ventral rumen sac. Rumen fluid was collected using a $100 \mathrm{ml}$ syringe that was connected to the silicone tube immediately before treatment as well as at 15, 60, 120, 180, 240, 480, 720 and $1440 \mathrm{~min}$ after each treatment. Before rumen fluid collection tubing was cleared from remaining fluid by injecting $100 \mathrm{ml}$ of air before aspirating approximately $50 \mathrm{ml}$ of rumen fluid. The silicone tube was clamped off after rumen fluid collection. Collected fluid was then transferred into a $10 \mathrm{ml}$ plastic tube and centrifuged within $30 \mathrm{~min}$ at $1500 \mathrm{~g}$ for $15 \mathrm{~min}$. A sample of the supernatant fraction was harvested and stored at $-24^{\circ} \mathrm{C}$ until analysed.

\section{Biochemical analysis}

Plasma concentrations of inorganic phosphate $\left(\mathrm{P}_{\mathrm{i}}\right.$, ammonium molybdate) and acetaminophen (AP, turbidimetric inhibition immunoassay) were determined spectrophotometrically, total Ca concentration was determined by indirect potentiometry (ion selective electrodes) using an automated analyser (DXC-600, Beckman Coulter Inc.). Total protein concentration was determined by refractometry using a temperaturecontrolled refractometer.

Rumen fluid was analysed for concentrations of $\mathrm{Ca}$ and $\mathrm{P}_{\mathrm{i}}$ as described for plasma using appropriate dilutions.

\section{Data analysis}

For each treatment the maximal plasma $P_{i}$ concentration $\left(\mathrm{C}_{\mathrm{P} \text { max }}\right)$ and the time to maximal plasma $\mathrm{P}_{\mathrm{i}}$ concentration $\left(T_{P \max }\right)$ were obtained from a plot of the plasma $P_{i}$ concentration-time data. Furthermore, the increment in plasma $\mathrm{P}_{\mathrm{i}}$ concentration relative to T0 $\left(\mathrm{C}_{\mathrm{PDiff}}\right)$ was calculated by subtracting the baseline $\mathrm{P}_{\mathrm{i}}$ concentration from the $\mathrm{P}_{\mathrm{i}}$ concentration measured at each time point and the maximal increment of plasma $P_{i}$ concentration $\left(C_{\text {PmaxDiff }}\right)$ was calculated by subtracting the baseline $P_{i}$ concentration from $C_{P \max }$. The areas under the plasma $P_{i}$ concentration increment-time curves for the first $120 \mathrm{~min}$ (AUC $\mathrm{PDiff}_{20}$ ) and $240 \mathrm{~min}\left(\mathrm{AUC}_{\mathrm{PDiff240}}\right)$ after treatment were calculated using the trapezoidal rule.

To characterise the plasma AP absorption curve the maximal AP concentration $\left(\mathrm{C}_{\mathrm{APmax}}\right)$ and the time to maximal AP concentration $\left(\mathrm{T}_{\mathrm{APmax}}\right)$ were derived from a plot of the plasma AP concentration-time data. The areas under the plasma AP concentration-time curves for the first $60 \mathrm{~min}$ $\left(\mathrm{AUC}_{\mathrm{AP} 60}\right)$ and $120 \mathrm{~min}\left(\mathrm{AUC}_{\mathrm{AP} 120}\right)$ after treatment were calculated as described above. 


\section{Statistical analysis}

Data are expressed as mean values with their standard errors or as medians and interquartile ranges for data that were not normally distributed. $P<0.05$ was considered to be significant. Values were log transformed when necessary to achieve a normal distribution. Repeated-measures ANOVA was used to detect differences in measured parameters between treatment groups and over time using an autoregressive (AR(1)) covariance matrix with animal ID as the repeated variable (PROC MIXED, SAS 9.2; SAS Institute, Inc.). Terms in the model used were treatment, time and the interaction of treatment and time. Post hoc tests were conducted to compare treatment, time and treatment-time interaction effects. Bonferronicorrected $P$ values were used to assess differences within and between treatment groups (within group compared with time $=0$; between groups at the same time). A statistical software package was used for all analyses (SAS 9.2; SAS Institute, Inc.).

\section{Results}

All cows enrolled in the present study completed the entire trial receiving all experimental treatments. Back-flow of fluid at the height of the omaso-abomasal orifice was noticed while infusing the test solution (CaAbo) into the abomasum of one cow. Analysis of plasma AP concentration-time curve as well as determination of $\mathrm{C}_{\mathrm{APmax}}$ for this specific treatment confirmed that the test solution was not entirely administered into the abomasum. Data obtained from this treatment were therefore excluded from data analysis.

The mean baseline plasma $P_{i}$ concentration at the end of the adaptation period immediately before the first treatment was $1 \cdot 12$ (sem $0 \cdot 16) \mathrm{mmol} / \mathrm{l}$. On the second, third, fourth and fifth study days baseline plasma $\mathrm{P}_{\mathrm{i}}$ concentrations were 1.23 (SEM $0 \cdot 11$ ), $1 \cdot 12$ (sem $0 \cdot 12$ ), 1.36 (sem $0 \cdot 10)$ and 1.23 (SEM $0 \cdot 11$ ) $\mathrm{mmol} / \mathrm{l}$. The baseline values did not differ significantly between treatment days.
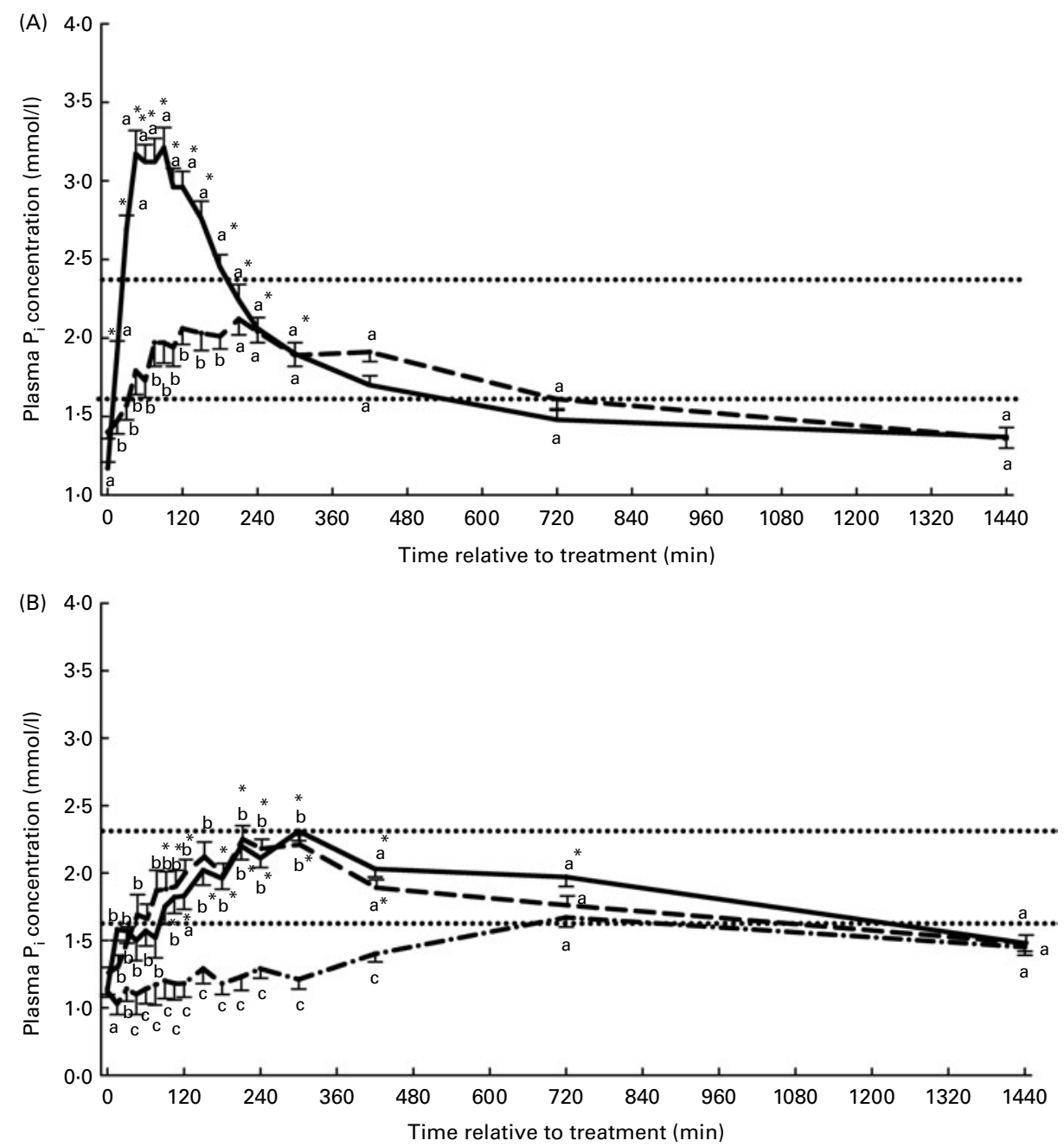

Fig. 1. Plasma phosphate concentration according to treatment and relative to baseline (TO) in the $\mathrm{NaH}_{2} \mathrm{PO}_{4}$ administered into the abomasum ( $\mathrm{NaAbo}$; A), $\mathrm{CaHPO}_{4}$ administered into the abomasum (CaAbo; - . - ; A), $\mathrm{NaH}_{2} \mathrm{PO}_{4}$ administered into the ventral rumen sac ( $\mathrm{NaRu}$; - ; $\mathrm{B}$ ), $\mathrm{NaH} \mathrm{PO}_{4}$ administered orally (NaOr; - - ; B) and $\mathrm{CaHPO}_{4}$ administered into the ventral rumen sac (CaRu; --_-; B) groups. ....., Upper and lower limits of the reference range for plasma inorganic phosphorus $\left(\mathrm{P}_{\mathrm{i}}\right)$ concentration in dairy cattle. Values are means, with their standard errors represented by vertical bars. ${ }^{*}$ Mean value was significantly different from that at T0 $\left(P<0.05\right.$, Bonferroni corrected). ${ }^{\text {a,b,c }}$ Mean values with unlike letters were significantly different between groups $(P<0.05)$. 
The plasma $P_{i}$ concentration-time curves stratified by treatment are presented in Figs. 1(A) and (B). The mean or median values for $\mathrm{C}_{\mathrm{Pmax}}, \mathrm{C}_{\mathrm{PmaxDiff}}, \mathrm{T}_{\mathrm{Pmax}}$ as well as $\mathrm{AUC}_{\mathrm{PDiff120}}$ and $\mathrm{AUC}_{\mathrm{PDiff} 240}$ are summarised in Table 2. Significant treatment, time and treatment-time effects were identified for plasma $P_{i}$ concentration, $C_{P_{\max }}$ and $C_{P \operatorname{maxDiff}}$ but not for $\mathrm{T}_{\text {Pmax }}$ (Table 2, Figs. 1(A) and (B)). Plasma $\mathrm{P}_{\mathrm{i}}$ concentration differed between groups with the exception of the $\mathrm{NaRu}$, NaOr and CaAbo groups. The highest, most rapid but also the most short-lived increases in plasma $P_{i}$ concentration were determined in the NaAbo group (Fig. 1(A), Table 2). In the CaAbo group similar values for $\mathrm{C}_{\mathrm{Pmax}}$ and $\mathrm{C}_{\mathrm{PmaxDiff}}$ were determined to those in the $\mathrm{NaRu}$ and $\mathrm{NaOr}$ groups (Table 2). Non-significant, delayed increases in plasma $P_{i}$ concentration were observed in the CaRu group (Fig. 1(B)) and $\mathrm{C}_{\text {PmaxDiff }}$ was lower in the CaRu group compared with the NaAbo and NaRu groups. The NaOr and NaRu groups showed very similar plasma $P_{i}$ concentration-time curves with significant increases in plasma $\mathrm{P}_{\mathrm{i}}$ concentration from 90 to 720 and from 120 to $340 \mathrm{~min}$, respectively (Fig. 1(B)). The $\mathrm{AUC}_{\mathrm{PDiff} 120}$ differed significantly between all groups with the exception of the $\mathrm{NaRu}$ and $\mathrm{NaOr}$ groups. The $\mathrm{AUC}_{\mathrm{PDiff120}}$ in these groups was lower than in the NaAbo group but higher than in the CaRu and CaAbo groups (Table 2). Plasma $\mathrm{P}_{\mathrm{i}}$ concentrations above the reference range for dairy cattle were only found in the NaAbo group.

The $\mathrm{C}_{\mathrm{APmax}}, \mathrm{T}_{\mathrm{APmax}}, \mathrm{AUC}_{\mathrm{AP} 60}$ and $\mathrm{AUC}_{\mathrm{AP} 120}$ characterising the AP absorption kinetics are summarised in Table 2. The plasma AP concentration-time curves are presented in Figs. 2(A) and (B). Significant treatment, time and treatment-time effects on plasma AP concentration were identified. Peak plasma AP concentration was significantly higher after intra-abomasal than after intraruminal treatment. A faster increase in plasma AP concentration was observed in the CaAbo group compared with the NaAbo group, with a significantly higher plasma AP concentration $15 \mathrm{~min}$ after treatment in the former group (Fig. 2(A)). No difference in AP absorption was observed between the two intraruminal treatments. Oral treatment resulted in lower AP concentration compared with both intra-abomasal treatments but similar AP concentration as measured after both intraruminal treatments (Figs. 2(A) and (B)). Accordingly, $\mathrm{C}_{\mathrm{APmax}}$ was the highest for the CaAbo and NaAbo groups, with values in the NaAbo group ranging approximately one-third below peak values determined in the CaAbo group (Fig. 2(A), Table 2). The $\mathrm{AUC}_{\mathrm{AP} 60}$ and $\mathrm{AUC}_{\mathrm{AP} 120}$ were higher after intra-abomasal treatment with either phosphate salt when compared with intraruminal or oral treatment with either salt but did not differ between the $\mathrm{CaRu}, \mathrm{NaRu}$ and $\mathrm{NaOr}$ groups. The $\mathrm{C}_{\mathrm{APmax}}$ and $\mathrm{AUC}_{\mathrm{AP} 120}$ in the NaOr group ranged barely $10 \%$ below values measured in the NaRu group (Table 2). The slope and amplitude of the plasma AP concentration-time curve were identical in the $\mathrm{NaRu}$ and $\mathrm{NaOr}$ groups for the first 120 min (Fig. 2(C)).

The plasma Ca concentration-time curves stratified by treatment are presented in Figs. 3(A) and (B). Treatment and time effects on plasma $\mathrm{Ca}$ concentration were significant, with the NaAbo group differing from all other groups, but with no differences between the remaining groups. Plasma Ca concentration in the NaAbo group was found to be significantly lower

Table 2. Maximal plasma acetaminophen concentration $\left(\mathrm{C}_{\mathrm{APmax}}\right)$, time to maximal plasma acetaminophen concentration $\left(\mathrm{T}_{\mathrm{APmax}}\right)$, areas under the plasma acetaminophen concentration-time curves for the first $60 \mathrm{~min}\left(\mathrm{AUC}_{\mathrm{AP} 60}\right)$ and $120 \mathrm{~min}\left(\mathrm{AUC} \mathrm{CP}_{\mathrm{AP} 120}\right)$ after treatment stratified by treatment group,

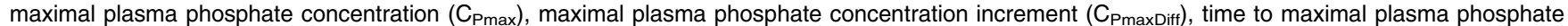
concentration $\left(T_{P \max }\right)$, and areas under the plasma phosphate concentration increment-time curves for the first 120 min (AUC $\left.C_{P D i f f 120}\right) 240$ min ( $\left.A \cup C_{P D i f f 240}\right), 420 \mathrm{~min}\left(\mathrm{AUC}_{\mathrm{PDiff420}}\right)$ and $720 \mathrm{~min}$ ( $\mathrm{AUC}_{\mathrm{PDiff720}}$ ) after treatment stratified by treatment group

(Mean values with their pooled standard errors of all groups or medians and interquartile ranges (IQR))

\begin{tabular}{|c|c|c|c|c|c|c|c|c|c|c|}
\hline \multirow[t]{2}{*}{ Treatment group. } & \multicolumn{2}{|c|}{ NaAbo } & \multicolumn{2}{|c|}{ CaAbo } & \multicolumn{2}{|c|}{$\mathrm{NaRu}$} & \multicolumn{2}{|c|}{$\mathrm{NaOr}$} & \multicolumn{2}{|c|}{$\mathrm{CaRu}$} \\
\hline & Mean & SEM & Mean & SEM & Mean & SEM & Mean & SEM & Mean & SEM \\
\hline \multicolumn{11}{|l|}{$\mathrm{C}_{\mathrm{APmax}}(\mu \mathrm{mol} / \mathrm{l})$} \\
\hline Median & \multirow{2}{*}{\multicolumn{2}{|c|}{$\begin{array}{c}188^{\mathrm{a}} \\
131.6-219 \cdot 8\end{array}$}} & \multicolumn{2}{|c|}{$257.9^{a}$} & \multicolumn{2}{|c|}{$53 \cdot 7^{\mathrm{b}}$} & \multirow{2}{*}{\multicolumn{2}{|c|}{$\begin{array}{c}47.0^{\mathrm{b}} \\
38 \cdot 7-59 \cdot 6\end{array}$}} & \multicolumn{2}{|c|}{$51 \cdot 8^{\mathrm{b}}$} \\
\hline IQR & & & \multicolumn{2}{|c|}{$193 \cdot 7-263.5$} & \multicolumn{2}{|c|}{$53 \cdot 3-72 \cdot 1$} & & & \multicolumn{2}{|c|}{$46 \cdot 7-65.8$} \\
\hline $\begin{array}{l}\mathrm{T}_{\mathrm{APmax}}(\mathrm{min}) \\
\mathrm{AUC}\end{array}$ & $65^{\mathrm{a}}$ & 8 & $48^{a}$ & 8 & $90^{\mathrm{a}, \mathrm{c}}$ & 8 & $100^{\mathrm{bc}}$ & 8 & $135^{\mathrm{b}}$ & 8 \\
\hline Median & \multicolumn{2}{|c|}{$537^{a}$} & \multicolumn{2}{|c|}{$772^{\mathrm{a}}$} & \multicolumn{2}{|c|}{$146^{\mathrm{b}}$} & \multicolumn{2}{|c|}{$126^{\mathrm{b}}$} & \multicolumn{2}{|c|}{$120^{\mathrm{b}}$} \\
\hline IQR & \multicolumn{2}{|c|}{$399-624$} & \multicolumn{2}{|c|}{$691-833$} & \multicolumn{2}{|c|}{$102-197$} & \multicolumn{2}{|c|}{$110-179$} & \multicolumn{2}{|c|}{$99-134$} \\
\hline \multicolumn{11}{|l|}{$\mathrm{AUC}_{\mathrm{AP} 120}(\mu \mathrm{mol} \times \mathrm{min} / \mathrm{l})$} \\
\hline Median & \multicolumn{2}{|c|}{$15302^{a}$} & \multicolumn{2}{|c|}{$19131^{a}$} & \multicolumn{2}{|c|}{$4882^{b}$} & \multicolumn{2}{|c|}{$4052^{b}$} & \multicolumn{2}{|c|}{$4296^{b}$} \\
\hline IQR & \multicolumn{2}{|c|}{$11541-16393$} & 16017 & 915 & 3771 & 51 & 3661 & & 3655 & 36 \\
\hline $\mathrm{C}_{\mathrm{P}_{\max }}(\mathrm{mmol} / \mathrm{l})$ & $3.52^{\mathrm{a}}$ & 0.11 & $2 \cdot 28^{\mathrm{b}}$ & 0.11 & $2 \cdot 29^{b}$ & 0.11 & $2 \cdot 39^{b}$ & 0.11 & $1.66^{\mathrm{b}}$ & 0.11 \\
\hline $\mathrm{C}_{\mathrm{PmaxD} \text { iff }}(\mathrm{mmol} / \mathrm{l})$ & $2 \cdot 34^{a}$ & $0 \cdot 11$ & $0.87^{\mathrm{b}, \mathrm{c}}$ & 0.11 & $1 \cdot 15^{\mathrm{b}}$ & $0 \cdot 11$ & $1.09^{b, c}$ & $0 \cdot 11$ & $0.55^{\mathrm{c}}$ & 0.11 \\
\hline $\mathrm{T}_{\mathrm{P} \max }(\min )$ & & & & & & & & & & \\
\hline Median & & & & & 25 & & & & & \\
\hline IQR & & & $90-$ & & 210 & & 210 & & 240 & \\
\hline$A \cup C_{P D i f f 120}(\mathrm{mmol} \times \mathrm{min} / \mathrm{l})$ & $192 \cdot 6^{\mathrm{a}}$ & $14 \cdot 2$ & $44.0^{\mathrm{b}}$ & $14 \cdot 2$ & $55.4^{c}$ & $14 \cdot 2$ & $50 \cdot 4^{\mathrm{c}}$ & $14 \cdot 2$ & $2.35^{d}$ & 14.2 \\
\hline AUC PDiff240 $(\mathrm{mmol} \times \mathrm{min} / \mathrm{l})$ & $350 \cdot 6^{a}$ & 22.9 & $121 \cdot 6^{\mathrm{b}}$ & 22.9 & $163 \cdot 7^{\mathrm{b}}$ & $22 \cdot 9$ & $152 \cdot 7^{\mathrm{b}}$ & 22.9 & $16 \cdot 4^{\mathrm{c}}$ & 22.9 \\
\hline AUC & $474 \cdot 1^{a}$ & $32 \cdot 8$ & $215 \cdot 2^{b}$ & $32 \cdot 8$ & $352 \cdot 5^{\mathrm{a}, \mathrm{b}}$ & 32.8 & $303 \cdot 6^{a, b}$ & $32 \cdot 8$ & $47 \cdot 1^{\mathrm{C}}$ & $32 \cdot 8$ \\
\hline AUC $_{\text {PDiff720 }}(\mathrm{mmol} \times \mathrm{min} / \mathrm{l})$ & $599 \cdot 1^{\mathrm{a}}$ & $45 \cdot 4$ & $322 \cdot 0^{\mathrm{a}, \mathrm{b}}$ & $45 \cdot 4$ & $612 \cdot 7^{\mathrm{a}}$ & $45 \cdot 4$ & $473 \cdot 6^{a}$ & $45 \cdot 4$ & $172 \cdot 1^{\mathrm{b}}$ & $45 \cdot 4$ \\
\hline
\end{tabular}

$\mathrm{NaAbo}, \mathrm{NaH}_{2} \mathrm{PO}_{4}$ administered into the abomasum; CaAbo, $\mathrm{CaHPO}_{4}$ administered into the abomasum; $\mathrm{NaRu}, \mathrm{NaH}_{2} \mathrm{PO}{ }_{4}$ administered into the ventral rumen sac; $\mathrm{NaOr}$,

$\mathrm{NaH}_{2} \mathrm{PO}_{4}$ administered orally; $\mathrm{CaRu}, \mathrm{CaHPO}_{4}$ administered into the ventral rumen sac.

a,b,c,d Values within a row with unlike superscript letters were significantly different $(P<0 \cdot 05$, Bonferroni corrected). 

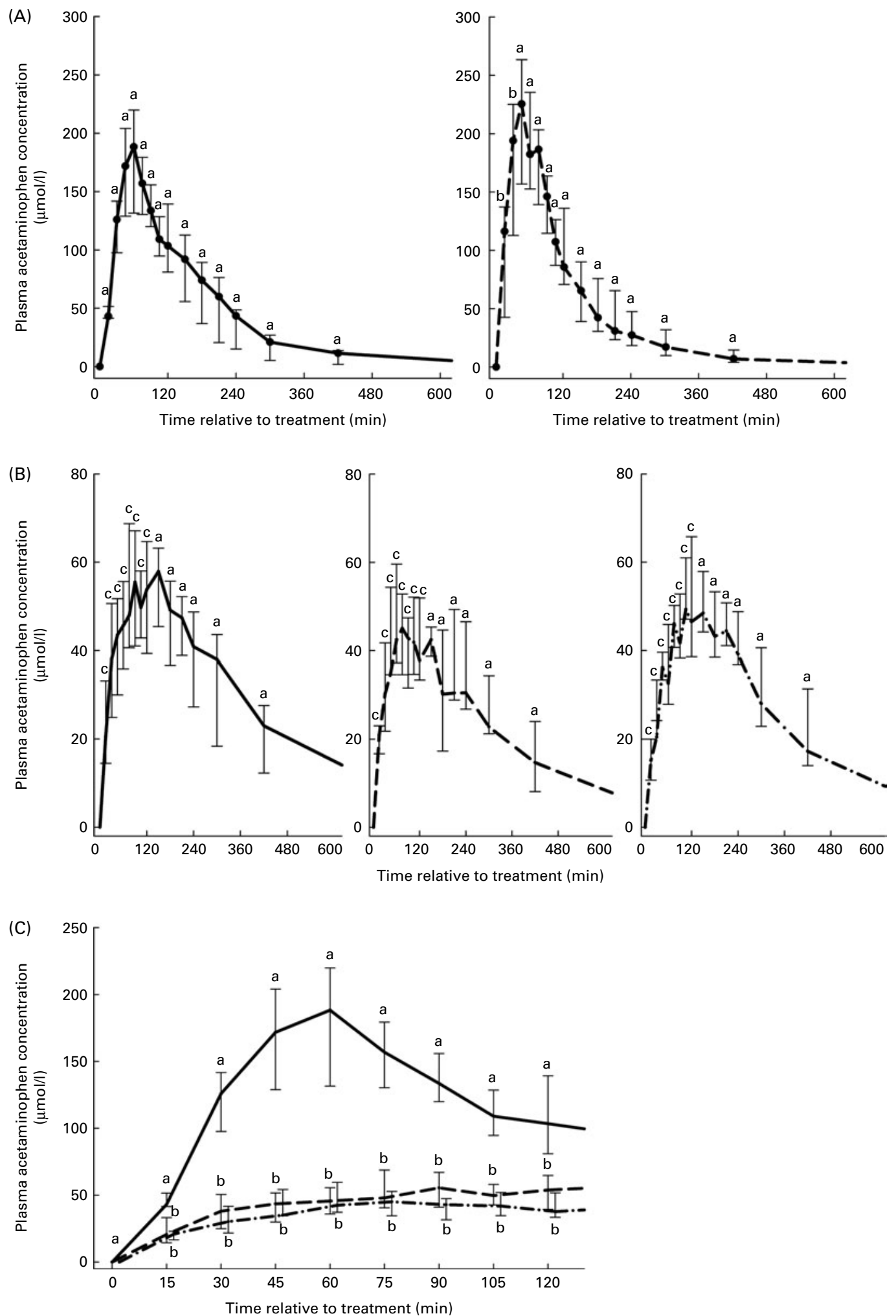

Fig. 2. Plasma acetaminophen concentration according to treatment and relative to baseline (TO) in the $\mathrm{NaH}_{2} \mathrm{PO}_{4}$ administered into the abomasum (NaAbo; A, left panel), $\mathrm{CaHPO}_{4}$ administered into the abomasum (CaAbo; - . ; A, right panel), $\mathrm{NaH}_{2} \mathrm{PO}_{4}$ administered into the ventral rumen sac (NaRu; - ; B, left panel), $\mathrm{NaH}_{2} \mathrm{PO}_{4}$ administered orally (NaOr; -.- ; B, middle panel) and $\mathrm{CaHPO}_{4}$ administered into the ventral rumen sac (CaRu; -.--; B, right panel) groups. Values are medians, with interquartile ranges represented by vertical bars. ${ }^{a, b, c}$ Median values with unlike letters were significantly different between groups $(P<0.05)$. (C) Detailed view of plasma acetaminophen concentration-time curves for the time period $0-120$ min for the NaAbo $(-)$, NaRu $(---)$ and $\mathrm{NaOr}$ $(---$,$) groups. Values are medians, with interquartile ranges represented by vertical bars. { }^{a, b}$ Median values with unlike letters were significantly different between groups $(P<0.05)$. Data of $\mathrm{NaOr}$ are slightly offset with respect to time to improve readability. 

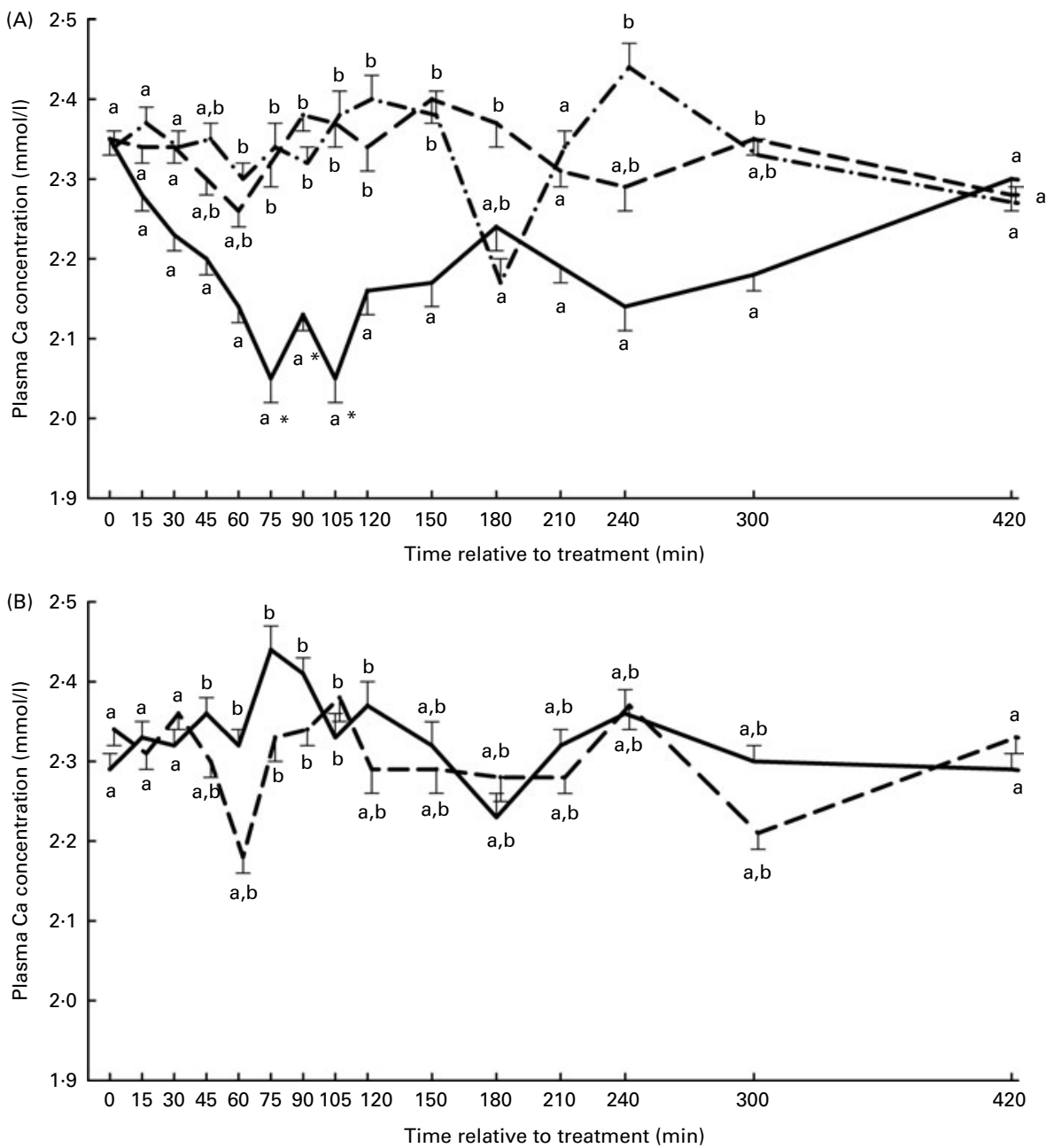

Fig. 3. Plasma calcium concentration according to treatment and relative to baseline (TO) in the $\mathrm{NaH}_{2} \mathrm{PO}_{4}$ administered into the abomasum (NaAbo; - ; A), $\mathrm{NaH}_{2} \mathrm{PO}_{4}$ administered into the ventral rumen sac (NaRu; -.-; A), $\mathrm{NaH}_{2} \mathrm{PO}_{4}$ administered orally (NaOr; ----; A), CaHPO ${ }_{4}$ administered into the abomasum $\left(\mathrm{CaAbo} ; \ldots\right.$ - B) and $\mathrm{CaHPO}_{4}$ administered into the ventral rumen sac (CaRu; - . ; B) groups. Values are means, with their standard errors represented by vertical bars. * Mean value was significantly different from that at T0 $\left(P<0.05\right.$, Bonferroni corrected). ${ }^{a, b}$ Mean values with unlike letters were significantly different between groups $(P<0.05)$.

compared with baseline values from 75 to $105 \mathrm{~min}$ after treatment (Fig. 3(A)).

Rumen $\mathrm{P}_{\mathrm{i}}$ concentration-time curves, stratified by treatment for groups having received phosphate salts either orally or into the rumen, are presented in Fig. 4. Treatment, time and treatment-time effects on the rumen $\mathrm{P}_{\mathrm{i}}$ concentration were significant. Rumen $P_{i}$ concentration was significantly increased relative to baseline values from 15 to $420 \mathrm{~min}$ and from 15 to 720 min post-treatment in the NaOr and $\mathrm{NaRu}$ groups, respectively. The CaRu, CaAbo and NaAbo treatments did not alter rumen $P_{i}$ concentration. Peak $P_{i}$ concentration in rumen fluid was significantly higher in the $\mathrm{NaRu}$ group (84.8 (SEM 24.4) mmol/1) compared with the NaOr group (30.8 (sem 3.6) $\mathrm{mmol} / \mathrm{l}$ ).

Rumen $\mathrm{Ca}$ concentration-time curves are presented in Fig. 5. A significant decline in rumen $\mathrm{Ca}$ concentration by over $50 \%$ was observed in the NaRu group within $15 \mathrm{~min}$ of treatment. A numerical decline in rumen $\mathrm{Ca}$ concentration observed in the NaOr group with a nadir 15 min after treatment was not significant (Fig. 5).

\section{Discussion}

The main objective of the study presented here was to study the absorption kinetics of phosphate after enteral administration of either $\mathrm{NaH}_{2} \mathrm{PO}_{4}$ or $\mathrm{CaHPO}_{4}$ from the bovine gastrointestinal tract and to evaluate the biological relevance of phosphate absorption from the bovine reticulorumen. Furthermore, it was intended to explore the role of the reticular groove reflex in phosphate absorption kinetics after oral administration of $\mathrm{NaH}_{2} \mathrm{PO}_{4}$. For this purpose a mildly P-deficient ration, containing $3.1 \mathrm{~g} \mathrm{P}_{\mathrm{i}} / \mathrm{kg}$ DM was fed for 1 week before starting experimental treatments to induce $P$ depletion in study animals. Mean baseline plasma $\mathrm{P}_{\mathrm{i}}$ concentrations obtained in the morning of each treatment day were below the reference for plasma $P_{i}$ concentration in cattle $(1.4-2.3 \mathrm{mmol} / \mathrm{l})$, suggesting that dietary $P_{i}$ content as well as the length of the acclimatisation period were sufficient to mildly deplete the cows of $\mathrm{P}_{\mathrm{i}}$ in the study.

An important finding of the present study was that approximately $300 \mathrm{~g} \mathrm{NaH}_{2} \mathrm{PO}_{4}$ rapidly increased plasma $\mathrm{P}_{\mathrm{i}}$ 


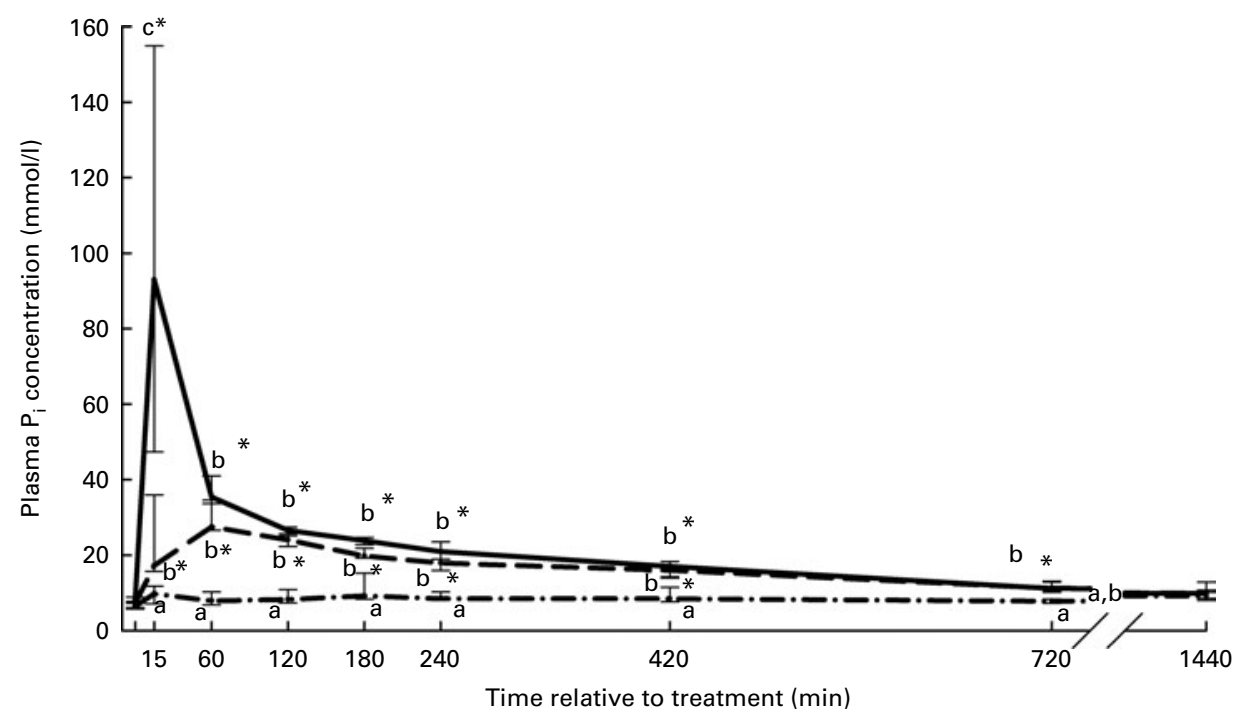

Fig. 4. Rumen phosphate $\left(\mathrm{P}_{\mathrm{i}}\right)$ concentration according to treatment and relative to baseline (T0) in the $\mathrm{NaH}_{2} \mathrm{PO}{ }_{4}$ administered into the ventral rumen sac ( $\mathrm{NaRu} ;-(-), \mathrm{NaH}_{2} \mathrm{PO}_{4}$ administered orally (NaOr; - - ) and $\mathrm{NaH}_{2} \mathrm{PO}_{4}$ administered into the abomasum (NaAbo; -.--) groups. Values are medians, with interquartile ranges represented by vertical bars. ${ }^{*}$ Median value was significantly different from that at T0 $\left(P<0.05\right.$, Bonferroni corrected). ${ }^{a, b, c}$ Median values with unlike letters were significantly different between groups $(P<0.05)$.

concentration in mildly phosphate depleted, but otherwise healthy, lactating dairy cows for at least $7 \mathrm{~h}$. This finding is in line with studies that monitored plasma $P_{i}$ concentration in healthy as well as hypocalcaemic cows after administrations of sodium phosphate via orogastric tube, where peak $P_{i}$ concentration were not measured earlier than $4 \mathrm{~h}$ posttreatment $^{(9,16)}$, but differs markedly from another study reporting peak plasma $\mathrm{P}_{\mathrm{i}}$ concentration within $1 \mathrm{~h}$ of oral treatment with $\mathrm{NaH}_{2} \mathrm{PO}_{4}{ }^{(8)}$.

Other studies reported no, or only very mild, effects on plasma $\mathrm{P}_{\mathrm{i}}$ concentration after oral administration of $\mathrm{Na}_{2} \mathrm{HPO}_{4}$ solutions but were either conducted on cows that were not $\mathrm{P}$ deficient and fed a ration with an adequate dietary $\mathrm{P}$ supply during the experiment or were treated with extremely low doses of $\mathrm{Na}_{2} \mathrm{HPO}_{4}(20 \mathrm{mg} / \mathrm{kg})^{(10,17)}$. Part of the discrepancy between the results presented in the present and other studies is likely to have resulted from the use of different sodium phosphate salts with different solubility and bioavailability. The considerably higher solubility of $\mathrm{NaH}_{2} \mathrm{PO}_{4}(869 \mathrm{~g} / \mathrm{l}$ water at $\left.20^{\circ} \mathrm{C}\right)$ when compared with $\mathrm{Na}_{2} \mathrm{HPO}_{4}(77 \mathrm{~g} / 1$ water at $20^{\circ} \mathrm{C}$ ) is likely to result in faster passage through the bovine forestomach system and increased bioavailability.

Assuming a turnover rate of $10 \%$ of the liquid phase of the rumen content perh, and an abomasal emptying rate of approximately $1 \mathrm{~h}$ in lactating dairy cows, a peak plasma $\mathrm{P}_{\mathrm{i}}$ concentration within $1 \mathrm{~h}$ after oral treatment with a solution containing $\mathrm{NaH}_{2} \mathrm{PO}_{4}$ is plausible only if the liquid either bypasses the reticulorumen, as this occurs with closure of the reticular groove, or by transruminal $\mathrm{P}_{\mathrm{i}}$ absorption in biologically relevant quantities ${ }^{(18,19)}$. In the present study direct administration of a $\mathrm{NaH}_{2} \mathrm{PO}_{4}$ solution into the abomasum, mimicking complete closure of the reticular groove, led to peak plasma $P_{i}$ concentration within approximately $1 \mathrm{~h}$, but plasma $P_{i}$ peaks were of considerably higher amplitude and of shorter duration when compared with the results of
Cheng et al. ${ }^{(8)}$ after oral drenching. Lower and more sustained peaks after oral drenching, as described by those authors, would be conceivable with partial closure of the reticular groove allowing a fraction of the test solution to bypass the reticulorumen with the remainder subsequently entering the small-intestinal tract after some delay having transited through the forestomach system. The AP concentration-time curve after intra-abomasal infusion revealed an abomasal emptying time of 50-60 min in the present study, which is in agreement with previously reported results ${ }^{(19,20)}$. In the present study we attempted to mimic complete closure of the reticular groove reflex by directly infusing a test solution into the abomasum. By bypassing the oral route this approach circumvents the stimulation of gastric relaxation and gastric accommodation, two reflexes triggered by the passage of food through the oesophagus, thereby causing relaxation of the stomach wall $^{(21)}$. With hampered gastric accommodation, direct infusion of 2 litres of fluid into the abomasum is likely to have resulted in a marked increase in abomasal luminal pressure, potentially forcing fluid from the abomasum into the duodenum $^{(22)}$. It is therefore probable that slopes of the plasma concentration-time curves for $\mathrm{AP}$ and $\mathrm{P}_{\mathrm{i}}$ determined after intra-abomasal infusion of the test solutions in the present study are steeper than what would be observed in healthy animals orally ingesting the same test solution with complete closure of the reticular groove.

Slope and amplitude of the AP concentration-time curve after oral administration of the test solution in the first $2 \mathrm{~h}$ after treatment were identical to the curve obtained after intraruminal treatment, but differed markedly from the curve obtained after intra-abomasal infusion (Fig. 2(C)). This result shows that AP absorption kinetics was the same after oral and intraruminal treatment and thus that only very little, if any, of the test solution can have bypassed the reticulorumen after oral treatment in the present experiment. 

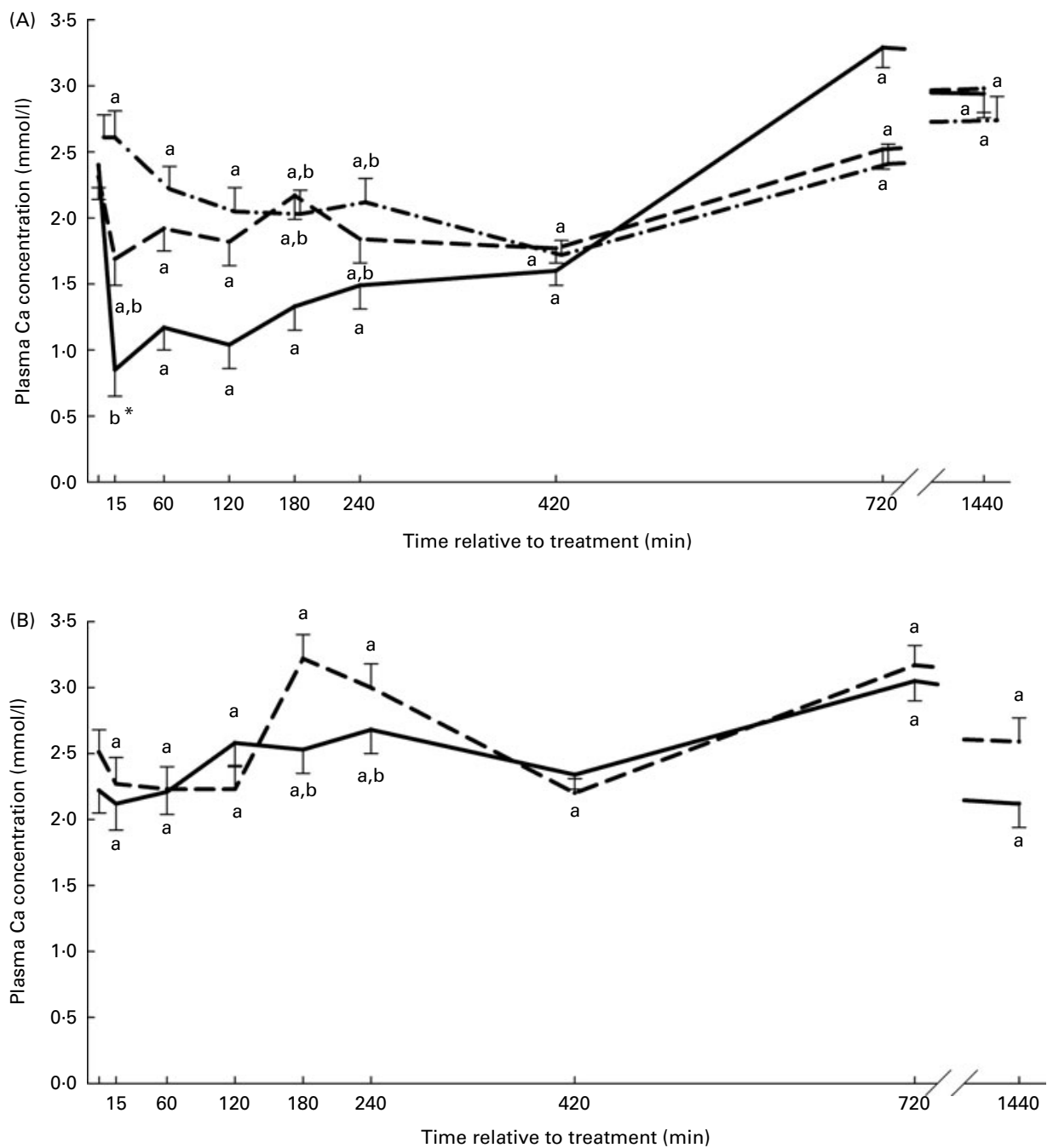

Fig. 5. Rumen calcium concentration according to treatment and relative to baseline (TO) in the $\mathrm{NaH}_{2} \mathrm{PO}_{4}$ administered into the ventral rumen sac (NaRu; - $; \mathrm{A}$ ), $\mathrm{NaH}_{2} \mathrm{PO}_{4}$ administered orally ( $\left.\mathrm{NaOr} ;-. ., \mathrm{A}\right), \mathrm{NaH}_{2} \mathrm{PO}_{4}$ administered into the abomasum (NaAbo; -..-; A), CaHPO administered into the abomasum (CaAbo; _ - B) and $\mathrm{CaHPO}_{4}$ administered into the ventral rumen sac (CaRu; - . ; B) groups. Values are means, with their standard errors represented by vertical bars. * Mean value was significantly different from that at T0 $\left(P<0.05\right.$, Bonferroni corrected). ${ }^{\text {a,b }}$ Mean values with unlike letters were significantly different between groups $(P<0.05)$.

Considering the previously mentioned turnover rate of the rumen liquid phase in lactating dairy cows of approximately $10 \%$ perh, and the fact that a certain but varying amount of orally ingested fluid always bypasses the rumen, a peak plasma $\mathrm{P}_{\mathrm{i}}$ concentration $4 \mathrm{~h}$ after oral treatment is conceivable without involvement of the reticular groove reflex and with no or minimal $\mathrm{P}_{\mathrm{i}}$ absorption from the reticulorumen ${ }^{(18,23)}$. An important clinical implication of these results is that the efficacy of oral phosphate supplementation at the dose and concentration used in the present study relies strongly on adequate rumen motility. With no or only minimal absorption of phosphate from the forestomach system, delayed rumen motility and thus delayed oroduodenal transit time are likely to hamper the efficacy of oral phosphate supplementation.

Several studies have reported that oral administration of solutions containing $\mathrm{Na}$ salts, such as $\mathrm{NaCl}$ or $\mathrm{NaHCO}_{3}$, were potentially able to trigger the reticular groove reflex in growing cattle up to 2 years of age ${ }^{(24,25)}$. In older cattle the effects of $\mathrm{Na}$ and other salts on the reticular groove appear to be inconsistent and to wane with age, but $\mathrm{NaHCO}_{3}$ solutions $(5.9 \mathrm{~mol} / \mathrm{l})$ were found to at least partially bypass the reticulorumen in the majority of treated animals ${ }^{(12)}$. Furthermore, clinical studies investigating the caustic effect of $\mathrm{Ca}$ salts used for oral Ca supplementation have suggested that calcium chloride may also at least incidentally trigger closure of the reticular groove even in older cows ${ }^{(16,26)}$. In the present study cows were drenched with 2 litres of a $1 \mathrm{M}-\mathrm{NaH}_{2} \mathrm{PO}_{4}$ solution whereas Cheng et al. ${ }^{(8)}$ used 0.5 litres of a $3 \mathrm{M}-\mathrm{NaH}_{2} \mathrm{PO}_{4}$ solution. Since osmolarity and taste of the solution administered into the bovine buccal cavity were among the possible factors contributing to closure of the reticular groove it is conceivable that at least part of the discrepancy between the present results and other studies is caused by this methodological difference ${ }^{(27)}$. 
Comparison of the slope of the concentration-time curves as well as the time to reach maximal plasma concentrations for $\mathrm{AP}$ and $\mathrm{P}_{\mathrm{i}}$ indicate that gastrointestinal absorption of $\mathrm{P}_{\mathrm{i}}$ is slower than AP absorption. Assuming that AP occurs predominantly in the proximal duodenum and that AP absorption from the forestomach system is near nil it can be concluded that phosphate absorption from the reticulorumen does not occur in biologically relevant quantities as this would have resulted in a steeper slope and earlier peak plasma $P_{i}$ concentration after intraruminal administration of the test solution compared with AP. The permeability of the mucosa of the reticulorumen for $\mathrm{P}_{\mathrm{i}}$ has been demonstrated in several studies $^{(28-30)}$. Nonetheless the physiological relevance of the reticulorumen as a site for $\mathrm{P}_{\mathrm{i}}$ absorption has been questioned, as only insignificant amounts of $\mathrm{P}_{\mathrm{i}}$ appear to cross the rumen wall $^{(11)}$. However, in vivo transruminal phosphate absorption has not been conclusively quantified.

As previously reported in the literature dicalcium phosphate $\left(\mathrm{CaHPO}_{4}\right)$ proved to be less effective than sodium phosphate salts to supplement $\mathrm{P}_{\mathrm{i}}$ orally in cattle ${ }^{(8)}$. With a maximal solubility of $0 \cdot 2 \mathrm{~g} / 1$ water at $25^{\circ} \mathrm{C}$ dicalcium phosphate is practically insoluble in water, explaining the nearly unchanged rumen $\mathrm{Ca}$ concentration and $\mathrm{P}_{\mathrm{i}}$ concentration after intraruminal administration of $\mathrm{CaHPO}_{4}$ measured in the present study. Sedimentation of the undissolved salt in the rumen is likely to explain the time delay and weak effect of this salt on the plasma $\mathrm{P}_{\mathrm{i}}$ concentration in treated cows. Administration of $\mathrm{CaHPO}_{4}$ directly into the abomasum, the compartment of the ruminant gastrointestinal tract with the highest acidity improved bioavailability of $\mathrm{P}_{\mathrm{i}}$ originating from $\mathrm{CaHPO}_{4}$ which nonetheless remained considerably lower than from $\mathrm{P}_{\mathrm{i}}$ substituted as $\mathrm{NaHPO}_{4}$. Improved bioavailability of $\mathrm{CaHPO}_{4}$ after intra-abomasal infusion when compared with intraruminal administration could be due to better solubility in acidic solution or just to the shorter oroduodenal transit time. Dicalcium phosphate that is frequently used in dairy cattle, presumably because it combines the administration of $\mathrm{P}_{\mathrm{i}}$ with $\mathrm{Ca}$, showed no measurable effects on either rumen or plasma Ca concentration.

The increase in plasma AP concentration was slower and the peak plasma AP concentration after intra-abomasal administration of $\mathrm{NaH}_{2} \mathrm{PO}_{4}$ was lower compared with peaks measured after administration of $\mathrm{CaHPO}_{4}$ solution of the same molarity directly into the abomasum. It is probable that this effect is due to the different solubility characteristics of the compounds used and the ensuing large difference in osmolarity of both test solutions. The abomasal emptying rate is strongly influenced by the osmolarity of the abomasal content ${ }^{(22)}$. Assuming a solubility for $\mathrm{NaH}_{2} \mathrm{PO}_{4}$ of $869 \mathrm{~g} / 1$ in water $\left(20^{\circ} \mathrm{C}\right) v \cdot 0 \cdot 2 \mathrm{~g} / \mathrm{l}$ in water $\left(20^{\circ} \mathrm{C}\right)$ for $\mathrm{CaHPO}_{4}$, a theoretical osmolarity for the test solution containing $\mathrm{NaH}_{2} \mathrm{PO}_{4}$ of approximately 2000 $\mathrm{mOsmol} / \mathrm{l}$ can be calculated compared with an osmolarity of $1.5 \mathrm{mOsmol} / 1$ for the solution containing $\mathrm{CaHPO}_{4}$.

Intra-abomasal administration $\mathrm{NaH}_{2} \mathrm{PO}_{4}$ showed the most rapid and strongest effects on plasma $\mathrm{P}_{\mathrm{i}}$ concentration, increasing it far above the reference range for $\mathrm{P}_{\mathrm{i}}$ in dairy cattle. Concomitantly a marked decline in plasma $\mathrm{Ca}$ concentration mirroring the increase in plasma $\mathrm{P}_{\mathrm{i}}$ concentration was observed after intra-abomasal treatment with $\mathrm{NaH}_{2} \mathrm{PO}_{4}$, a well-described complication of hyperphosphataemia associated with the precipitation of excessive amounts of $\mathrm{P}_{i}$ as calcium phosphate ${ }^{(31)}$.

Peak rumen $\mathrm{P}_{\mathrm{i}}$ concentration after oral and intraruminal treatment with $\mathrm{NaH}_{2} \mathrm{PO}_{4}$ of approximately 30 and $80 \mathrm{mmol} / \mathrm{l}$, respectively, were measured 15 min after treatment. Assuming an average volume of the liquid phase of the reticulorumen of 90 litres in a lactating dairy cow, administration of approximately $2000 \mathrm{mmol} \mathrm{P}_{\mathrm{i}}$ would have increased the $\mathrm{P}_{\mathrm{i}}$ concentration in rumen fluid by approximately $22 \mathrm{mmol} / \mathrm{l}$ to a total of $32 \mathrm{mmol} / \mathrm{l}^{(18)}$. It is therefore proposed that peak concentrations measured in the ventral rumen sac after intraruminal administration of the test solution containing $\mathrm{NaH}_{2} \mathrm{PO}_{4}$ are not representative of the entire fluid phase of the reticulorumen, but are an artifact of incomplete mixing of the rumen content during the first $15 \mathrm{~min}$. Accordingly the marked decline in $\mathrm{Ca}$ concentration in the ventral rumen sac noted after intraruminal administration of $\mathrm{NaH}_{2} \mathrm{PO}_{4}$, which presumably was caused by precipitation of calcium phosphate, is unlikely to reflect the mean $\mathrm{Ca}$ concentration in rumen fluid after complete mixing. Much milder declines of rumen $\mathrm{Ca}$ concentration were measured in the ventral rumen sac after oral treatment, which are more likely to reflect average $\mathrm{Ca}$ concentration of the rumen fluid. Neither oral nor intraruminal treatment with $\mathrm{NaH}_{2} \mathrm{PO}_{4}$ had a noticeable effect on the Ca concentration in plasma in treated animals.

During oral administration of the test solution with a drench gun an undetermined volume of test solution was lost as it drooled out of the buccal cavity of treated animals. By comparing peak plasma AP concentration as well as the area under the plasma AP concentration-time curve after oral and intraruminal treatment we crudely estimated that the mean volume lost during oral administration cannot have exceeded $10 \%$ of the administered volume as for both parameters values obtained after oral treatment were less than $10 \%$ below values measured after intraruminal treatment. Losses of $\mathrm{NaH}_{2} \mathrm{PO}_{4}$ while drenching cows could potentially also explain lower peak plasma $\mathrm{P}_{\mathrm{i}}$ concentration as well as area under the plasma $\mathrm{P}_{\mathrm{i}}$ concentration curve when compared with intraruminal administration of $\mathrm{NaH}_{2} \mathrm{PO}_{4}$.

Acetaminophen ( $\mathrm{N}$-acetyl-4-aminophenol) is a widely used analgesic and antipyretic agent that is absorbed from the proximal small-intestinal tract but not from the stomach in single-stomached species when administered orally ${ }^{(15)}$. Determination of specific parameters characterising the absorption kinetics of AP such as the plasma AP concentration at specific times, $\mathrm{C}_{\mathrm{APmax}}, \mathrm{T}_{\mathrm{APmax}}$ or area under the $\mathrm{AP}$ concentration-time curve for different time intervals after oral treatment have been validated as indirect quantitative parameters for gastric emptying after administration of liquid meals in humans and other single-stomached species including pre-ruminating calves ${ }^{(22,32)}$. The acetaminophen absorption test (APAT) consisting of oral administration of a liquid containing AP and subsequent repeated blood sample collections to obtain a plasma AP concentration-time curve has also been used in adult and juvenile bovines and in goat kids to study the function of the reticular groove reflex $^{(32-35)}$. Whereas in 
single-stomached species the plasma AP concentration is mainly the result of overlapping processes such as intestinal absorption and metabolism and excretion in liver and kidney, respectively, in ruminants absorption from the reticulorumen is a potential confounder that has not been studied in detail $^{(33,36)}$. The flat slope and low amplitude of the AP concentration-time curve after administration of a test solution containing AP into the rumen compared with curves obtained after AP administration directly into the abomasum either by direct infusion or stimulation of the reticular groove reflex led to the widely held assumption that the amount of AP absorbed from the reticulorumen is negligible, if not nil ${ }^{(31-33)}$. The $T_{A P \max }$, which is a main outcome variable of the APAT and frequently referred to as gastric emptying time, in ruminants is more appropriately referred to as 'oroduodenal transit time' since the appearance of AP in plasma in ruminants is not mainly driven by the abomasal emptying rate but also depends on either rumen motility or function of the reticular groove reflex ${ }^{(33,34)}$. In calves and goat kids significantly higher and earlier $\mathrm{C}_{\mathrm{APmax}}$ values have been reported in animals with a functional reticular groove after oral AP administration $^{(32,34)}$. Another study conducted in cannulated dairy cows also reported significantly higher AP peaks after intra-abomasal compared with intraruminal administration of an AP-containing solution, suggesting that the APAT is a valuable, cheap and minimally invasive tool to study the activation of the reticular groove reflex in ruminants 34,35$)$

In conclusion, it is reported that the treatment with approximately $300 \mathrm{~g} \mathrm{NaH}_{2} \mathrm{PO}_{4}$ dissolved in 2 litres of water and administered as an oral drench is suitable to correct hypophosphataemia in mildly $\mathrm{P}_{\mathrm{i}}$-depleted dairy cows for approximately $8 \mathrm{~h}$. Peak concentrations after oral treatment are observed $4 \mathrm{~h}$ after treatment, indicating that neither transruminal $\mathrm{P}_{\mathrm{i}}$ absorption nor stimulation of the reticular groove reflex affected the absorption kinetics of orally administered $\mathrm{NaH}_{2} \mathrm{PO}_{4}$ at the dose and concentration used in the present study. Dicalcium phosphate administered into the rumen is of little use as a $\mathrm{P}_{\mathrm{i}}$ supplement in dairy cows.

\section{Acknowledgements}

The present study was conducted at the Department for Farm Animal Health, Utrecht University, Yalelaan 7, 3584C N Utrecht, The Netherlands.

The present study was partially supported by Boehringer Ingelheim Vetmedica GmbH, Ingelheim, Germany. This sponsor had no involvement in study design, the collection, analysis or the interpretation of data, writing the report, or the decision to submit the report for publication.

The responsibilities of the authors were as follows: W. G. designed and carried out the study as well as the data analysis and wrote the paper. P. D. contributed to designing the study, formulated the experimental ration and contributed to the manuscript. G. B. contributed to designing the study and writing the manuscript. All authors read and approved the final manuscript.

The authors declare not to be subject to any conflict of interest.

\section{References}

1. El-Amrusi S \& Hofmann W (1970) Untersuchung über das Festliegen der Rinder. 1. Bestimmung des Natriums, Kaliums, Kalziums und Magnesiums sowie anorganischen Phosphors im Blutserum gesunder Rinder (Investigation into downer cattle. Determination of sodium, potassium, calcium and magnesium and inorganic phosphorus in the blood serum of healthy cattle). Dtsch Tierärztl Wochenschr 77, 49-53.

2. Satter LD (2002) What goes in must come out - phosphorus balance on dairy farms. In Proceedings of the 35th Annual Conference of the American Association of Bovine Practitioners, pp. 125-130. Stillwater, OK: American Association of Bovine Practitioners.

3. Wu Z \& Satter LD (2000) Milk production and reproductive performance of dairy cows fed two concentrations of phosphorus for two years. J Dairy Sci 83, 1052-1063.

4. Grünberg W (2008) Phosphorus homeostasis in dairy cattle: some answers, more questions. In Proceedings of the 17 th Annual Tri-state Dairy Nutrition Conference, pp. 29-35. Fort Wayne, IN: Ohio State University, Michigan State University and Purdue University.

5. Grünberg W, Constable PD, Schröder U, et al. (2005) Phosphorus homeostasis in dairy cows with abomasal displacement or abomasal volvulus. J Vet Int Med 19, 894-898.

6. Grünberg W, Staufenbiel R, Constable PD, et al. (2009) Liver phosphorus content in Holstein Friesian cows during the transition period. J Dairy Sci 92, 2106-2117.

7. Milton JTB \& Ternouth JH (1985) Phosphorus metabolism in ruminants. 2. Effects of inorganic phosphorus concentration upon food intake and digestibility. Aust J Agric Res 36, 647-654.

8. Cheng YH, Goff JP \& Horst RL (1998) Restoring normal blood phosphorus concentrations in hypophosphatemic cattle with sodium phosphate. Vet Med 93, 383-388.

9. Braun U, Dumelin J, Liesegang A, et al. (2007) Effects of intravenous calcium and oral sodium phosphate on electrolytes in cows with parturient paresis. Vet Rec 161, 490-492.

10. Horner S \& Staufenbiel R (2004) Über die Wirksamkeit oraler und subkutaner Phosphorsubstitutionen beim Rind (About the effectiveness of oral and subcutaneous phosphorus substitutions in cattle). Prakt Tierarzt 85, 761-767.

11. Yano F, Yano H \& Breves G (1989) Calcium and phosphorus metabolism in ruminants. In Proceedings of the Seventh International Symposium on Ruminant Physiology, pp. 277-295. New York: Academic Press.

12. Carruthers VR, Phipps DE \& Bakker RJ (1994) The effect on oesophageal groove closure of water and mineral solutions drenched to cows. Proc New Zealand Soc Anim Prod 54, $23-26$.

13. National Research Council (2001) Nutrient Requirements of Dairy Cattle, 7th revised ed. Washington, DC: National Academy Press.

14. Constable PD (2003) Fluid and electrolyte therapy in ruminants. Vet Clin Food Anim 19, 557-597.

15. Clements JA, Heading RC, Nimmo WS, et al. (1978) Kinetics of acetaminophen absorption in man. Clin Pharamcol Ther 24, 420-431.

16. Braun U, Bryce B, Liesegang A, et al. (2008) Untersuchung zur Prophylaxe der Gebärparese mit Kalzium und Natriumphosphat per os (Investigation on the prevention of milk fever with oral calcium and sodium phosphate). Schweiz Arch Tierbeilk 150, 331-338.

17. Jagadeeswaran A \& Jagadishkumar B (1989) Influence of single administration of phosphorus salts on serum and 
urinary inorganic phosphorus levels in dairy heifers - a comparative study. Indian Vet J 75, 912-914.

18. Hartnell GF \& Satter LD (1979) Determination of rumen fill, retention time and ruminal turnover rates of ingesta at different stages of lactation in dairy cows. J Anim Sci $\mathbf{4 8}$, 381-392.

19. Wittek T, Schreiber K, Fürll M, et al. (2005) Use of the d-xylose absorption test to measure abomasal emptying in healthy lactating Holstein-Friesian cows and in cows with left displaced abomasums or abomasal volvulus. $J$ Vet Intern Med 19, 905-913.

20. Ehsani-Kheradgerdi A, Sharifi K, Mohri M, et al. (2011) Evaluation of a modified acetaminophen absorption test to estimate the abomasal emptying rate in Holstein-Friesian heifers. Am J Vet Res 72, 1600-1606.

21. Olsson C \& Holgren S (2001) The control of gut motility. Comp Biochem Physiol A 128, 481-503.

22. Marshall TS, Constable PD, Crochick SS, et al. (2005) Determination of abomasal emptying rate in suckling calves by use of nuclear scintigraphy and acetaminophen absorption. Am J Vet Res 66, 364-374.

23. Woodford ST, Murphy MR, Davis CL, et al. (1984) Ruminal bypass of drinking water in lactating cows. J Dairy Sci $\mathbf{6 7}$, $2471-2474$

24. Wester J (1930) The rumination reflex in the ox. Vet J 86, 401-410.

25. Reik RF (1954) The influence of sodium salts on the closure of the oesophageal groove in calves. Aust Vet J 30, 29-37.

26. Wentink GH \& van den Ingh TSGAM (1992) Oral administration of calcium chloride-containing products: testing for deleterious side-effects. Vet Quart 14, 76-80.

27. Titchen DA \& Newhook JC (1975) Physiological aspects of suckling and the passage of milk through the ruminant stomach. In Proceedings of the Fourth International Symposium on Ruminant Physiology, Sydney, Australia, pp. 101-115. Armidale, NSW: University of New England Publishing Unit.

28. Breves G, Gäbel G, Martens H, et al. (1986) Phosphate fluxes across the rumen wall mucosa of sheep in vitro. Proc Nutr Soc 45, A99

29. Breves G, Holler H, Packheiser P, et al. (1988) Flux of inorganic phosphate across the sheep rumen wall in vivo and in vitro. Quart J Exp Physiol Cogn Me Sci 73, $343-351$

30. Beardsworth LJ, Beardsworth PM \& Care AD (1989) The effect of ruminal phosphate concentration on the absorption of calcium, phosphorus and magnesium from the reticulorumen of the sheep. BrJ Nutr 61, 715-723.

31. Goff JP (1999) Treatment of calcium, phosphorus and magnesium balance disorders. Vet Clin Food Anim 15, 619-639.

32. Sharifi K, Grünberg W, Soroori S, et al. (2009) Assessment of the acetaminophen absorption test as a diagnostic tool for evaluation of the reticular groove reflex in lambs. Am J Vet Res 70, 820-825.

33. Schaer S, Herrli-Gygi M, Kosmeas N, et al. (2005) Characteristics of acetaminophen absorption in healthy unweaned calves as an indirect measurement of the oroduodenal transit rate of liquid meals. $J$ Vet Med A 52, 325-332.

34. Herrli-Gygi M, Steiner A, Doherr MG, et al. (2008) Digestive processes in ruminal drinkers characterized by means of the acetaminophen absorption test. Vet J 176, 369-377.

35. Bakker BJ, Jorritsma R, Tielens AGM, et al. (2010) Ability of different salts or dextrose and high osmolarity of solutions administered orally to trigger the reticular groove reflex in adult cattle. In Proceedings of the 14th International Conference on Production Diseases in Farm Animals, p. 110 [G Opsomer, editor]. Ghent: University Press.

36. Forrest JAH, Clements JA \& Prescott LF (1982) Clinical pharmacokinetics of paracetamol. Clin Pharmacokinet $\mathbf{7}$, 97-107. 